\title{
A IMPORTÂNCIA DO DISCURSO NA FORMAÇÃO DE CONCEITOS E VALORES SOCIAIS
}

\author{
MARIA DAS DORES AGUIAR CARVALHO ${ }^{1}$
}

RESUMO: O presente trabalho centraliza seu foco especificamente no discurso e sua importância na formação de conceitos e valores sociais. Acredito na relevância desta temática de estudo, considerando que a sociedade vive atualmente um período de mudanças de conceitos e valores, sendo que por isso muitos discursos estão sendo mudado. Neste trabalho procura-se mostrar como os discursos tem influenciado a sociedade. Sendo que no decorrer deste projeto vamos buscar respostas para os seguintes problemas da pesquisa: a) O que entendemos por discurso? b) Qual a importância do discurso para a formação individual e coletiva? c) Como a sociedade tem sido influenciada pelo discurso? Desse modo, precisamos cada vez mais olhar para os problemas sociais a partir de uma análise sobre a construção e circulação de sentidos do social através da linguagem em nossas práticas culturais, pois, nessas práticas, ideologias são materializadas, sendo reproduzidas ou contestadas por meio dos nossos discursos. Sendo assim, neste trabalho trago um modelo de análise linguística aberto ao tratamento de práticas da vida social, pois nos permite mapear as relações entre os recursos linguísticos usados por diferentes atores sociais.

Palavras - Chave: Discurso. Sociedade. Valores sociais. Formação coletiva.

ABSTRACT: The present work focuses specifically on discourse and its importance in the formation of social concepts and values. I believe in the relevance of this topic of study, considering that society is currently experiencing a period of changes in concepts and values, and that is why many discourses are being changed. This work seeks to show how speeches have influenced society. In the course of this project, we will seek answers to the following research problems: a) What do we

\footnotetext{
${ }^{1}$ Formada em Letras pela Universidade Estadual do Maranhão; Tem especialização em Docência do Ensino Superior e Planejamento Educacional (pela Universidade Aberta do Brasil) e é Especialista em Educação Inclusiva (pela Universidade Católica Dom Bosco) e atua como Professora de Língua Portuguesa da rede Estadual e Municipal no município de São Bento -MA, desde 1997. E-mail: I2dorinha.carvalho@gmail.com
} 
mean by discourse? b) What is the importance of discourse for individual and collective formation? c) How has society been influenced by discourse? Thus, we increasingly need to look at social problems from an analysis of the construction and circulation of social meanings through language in our cultural practices, because, in these practices, ideologies are materialized, being reproduced or contested through the our speeches. Therefore, in this work I bring a linguistic analysis model open to the treatment of social life practices, as it allows us to map the relationships between the linguistic resources used by different social actors.

Keywords: Discourse. Society. Social values. Collective formation.

\section{INTRODUÇÃO}

$\mathrm{Na}$ década de sessenta, os estudiosos analisavam os textos de acordo com a história, relacionavam Linguística, Marxismo e Psicanálise. Sendo assim, a análise do discurso nasceu com um caráter interdisciplinar. E essa interdisciplinaridade vem do fato de a análise do discurso relacionar, unir, o linguístico com o social, fazendose necessária a contribuição de outras áreas do conhecimento para auxiliar a Linguística.

Acredita-se que cada vez mais os Estudos da Linguagem necessitam voltar-se para o cotidiano a partir do entendimento de que a linguagem é uma prática social. Esse entendimento nos leva a perceber que muitas das questões que afligem o nosso tempo, como a violência de gênero, por exemplo, têm sua feição linguística

Pêcheux (1997) afirma que discurso é efeito de sentido entre locutores, o que significa que aí saímos do conceito do esquema elementar da comunicação, em que temos apenas o locutor transmitindo mensagem através de um código (língua) para o receptor, e entramos na transmissão em que há efeitos de sentidos entre locutores, efeitos estes que resultam da relação de sujeitos simbólicos que participam do discurso, dentro de circunstâncias dadas. Ainda segundo Pêcheux (ibidem), um discurso é sempre pronunciado a partir de condições de produção dadas, que abarcam os sujeitos e a situação. Orlandi (2009), apresenta as condições de produção em 
sentido estrito que é "o contexto imediato", ou seja, onde e em que situação os sujeitos se encontram, e o sentido amplo considera o contexto histórico, levando em consideração, também, a memória, que define o que já é sabido, o já dito. Ainda segundo Orlandi, os sentidos estrito e amplo são indissociáveis. De acordo com ela ( Orlandi;1996, p.12),

“é pelo discurso que melhor se compreende a relação entre linguagem/pensamento/mundo, porque o discurso é uma das instâncias materiais (concretas) dessa relação".

Então, o discurso é efeito de sentido e o sentido do discurso não é fixo, mas, sim, encontra-se sempre aberto para a possibilidade de interpretação. Dessa forma, segundo Orlandi (ibidem), do ponto de vista da significação, a relação do homem com o pensamento, com a linguagem e com o mundo não é direta. O modo como é atribuído o sentido depende da interpretação, porém, por um efeito ideológico, temos a ilusão de que ela tem um sentido único e isso acontece porque as condições de produção definem o movimento interpretativo. Desta maneira, este ato individual de utilização e apropriação da língua introduz aquele que fala em sua própria fala. Por isso a presença do locutor em sua alocução permite que a instância de discurso se torne um ponto de referência interno, pois ressalta a constante relação do locutor com a sua enunciação.

O desejo de tornar seu discurso inteligível é apenas um elemento abstrato da intenção discursiva em seu todo. O próprio locutor como tal é, em certo grau, um respondente, pois não é o primeiro locutor, que rompe pela primeira vez o eterno silêncio de um mundo mudo, e pressupõe não só a existência do sistema da língua que utiliza, mas também a existência dos enunciados anteriores [...] (BAKHTIN 2000, p.29I). A principal forma de comunicação da humanidade é a língua, e esta é desempenhada em forma de enunciados (orais ou escritos). Segundo Bakhtin (2000, p.279), o enunciado reflete o modo de vida e as intenções de cada esfera da atividade humana. Assim, entendemos que através do estudo dos discursos proferidos nas várias esferas da atividade humana podemos entender as vivências, o modo de pensar e agir, a cultura, a ideologia, e, também como esses discursos perpassam as sociedades. 
Segundo Fernandes, o discurso não é a língua ou o texto em si, mas materializa-se neles. Podemos afirmar que discurso tomado como objeto da Análise do Discurso, não é a língua, nem texto, nem a fala, mas que necessita de elementos linguísticos para ter uma existência material. Com isso, dizemos que discurso implica numa exterioridade à língua, encontra-se no social e envolve questões de natureza não estritamente linguísticas. (FERNANDES, 2005, p.20).

Para Orlandi (1999, apud FERNANDES, 2005, p. 22), “O discurso é assim palavra em movimento, prática de linguagem: com o estudo do discurso observa-se o homem falando".

Sendo assim, entendemos o discurso como sendo as palavras, as ideias, a visão do homem diante do mundo, mesmo que não estejam materializadas em um texto, por exemplo. Portanto, para estudarmos um discurso devemos analisar os elementos linguísticos em que ele se torna material. E esses elementos linguísticos encontram-se no social, na relação do homem com seu contexto sócio histórico, dessa forma, eles, sempre sofrem influências do meio em que estão inseridos, pois compreendemos que nenhum discurso é neutro, mas perpassado por outros discursos. Isso porque sendo o discurso a linguagem em interação, seu estudo não pode ser desvinculado das práticas sociais que o envolvem. Analisar os discursos é pensar na relação entre homem, história e sociedade. As práticas sociais é que vão determinar os efeitos de sentido que um determinado discurso pode ter.

Segundo as teorias da Análise do Discurso, os sentidos de um discurso não podem ser encontrados nele mesmo, é necessário recordar outros discursos que nele interferem. O discurso é entendido como a linguagem em interação, ou seja, a linguagem enquanto discurso não é apenas um instrumento de comunicação, mas uma produção de um determinado grupo social influenciado por uma ideologia. $O$ discurso é a palavra em movimento, portanto para se estudar o discurso é necessário observar o homem integrado em suas práticas sociais. Em outras palavras, o discurso é a linguagem produzida pelos indivíduos em seus contextos específicos, com suas características políticas e ideológicas. 
Ao analisar um discurso, o estudioso deve pesquisar as suas condições de produção, isto é, estudar os sujeitos da enunciação, a época e o lugar onde estão inseridos, pois de acordo com quem e de onde se enunciam ou são enunciados os sentidos do discurso são diferentes. Nas palavras de Fernandes (2005),

\begin{abstract}
o lugar histórico-social em que os sujeitos enunciadores de determinado discurso se encontram envolve o contexto e a situação e intervém a título de condições de produção do discurso. Não se trata da realidade física e sim de um objeto imaginário socioideológico. (FERNANDES, 2005, p.28).
\end{abstract}

Diante disso, segundo o autor, para iniciar uma reflexão sobre o discurso é necessário compreender os conceitos de sentido, enunciação, ideologia, condições de produção e sujeito discursivo. Fernandes (2005) define enunciação como sendo o lugar sócio- histórico-ideológico de onde os sujeitos enunciam. E sentido: trata-se do efeito de sentido entre sujeitos em enunciação, dessa forma, nega-se a ideia de mensagem encerrada em si.

O sentido de um discurso não é encontrado nele mesmo, pois ele não é neutro, sofre influências externas. Para Leite (200I, p. IIo), "a interpretação completa dos sentidos de um texto ou de um conjunto de textos é impossível”, isso se deve ao fato de um texto sempre retomar outro e mais outro. Um texto encerra em si pensamentos de outros autores, conforme Leite, o sentido não está no texto, mas na relação que este mantém com quem o produz, com quem o lê, com outros textos (intertextualidade) e como outros discursos possíveis (interdiscursividade). Por isso, ao se debruçar sobre um arquivo textual, o analista do discurso faz um "gesto de interpretação", a fim de construir um dispositivo teórico-analítico, através do qual faça emergir o mosaico de sentidos que caracteriza a heterogeneidade enunciativa. (LEITE, 200I, p.IIo ).

Segundo Fiorin (2006,p. 19), “ não há nenhum objeto que não apareça cercado, envolto, embebido em discursos", isto é, tudo ao nosso redor é perpassado por ideias, pontos de vista, críticas ou avaliações de outros. Portanto, todo discurso proferido dialoga com outros que antes existiram. Fiorin, iluminado pelas teorias de Bakhtin, diz que "dialogismo são as relações de sentido que se estabelecem entre dois enunciados." (FIORIN, 2006, p.19). 
O sentido que não está no texto, como vimos acima com Leite, pode ser encontrado quando analisamos o dialogo deste com os outros que estão ao seu redor, na história. A História não é exterior ao sentido, mas é interior a ele, pois ele é que é histórico, já que se constitui fundamentalmente no confronto, na contradição, na oposição das vozes que entrechocam na arena da realidade. (FIORIN, 2006, p.59)

É sabido que a linguagem, metaforicamente, é reconhecida como a roupagem que, por vezes camufla o verdadeiro sentido, o verdadeiro conteúdo do objeto. $\mathrm{Na}$ análise de um discurso em uso pode-se, ainda recuperar representações humanas e ideológicas que dotam a palavra de uma forca transcendental e mística subjacente ao acervo cultural de uma comunidade.

O discurso pode ser abordado, segundo Resende e Ramalho (2006, p. I2) a partir de dois paradigmas: o formalista e o funcionalista. Sendo assim, ele possui um conceito diferente dependendo de em qual paradigma está inserido. Se no formalista, ele é entendido como "a unidade acima da sentença” (RESENDE e RAMALHO, 2006, p. 13), ou seja, o texto em si. O paradigma formalista é encarregado de analisar a linguagem como um objeto autônomo, em que seus módulos (por exemplo morfologia, fonologia) não se relacionam, já que também são objetos independentes. Já o paradigma funcionalista estabelece que a linguagem dialoga com elementos externos a ela, ou seja, ela não é autônoma, uma vez que tem relações com elementos sociais. Para a Análise do Discurso Crítica interessa o paradigma funcionalista, contudo é válido ressaltar a importância da busca pelo equilíbrio entre forma (paradigma formalista) e função (paradigma funcionalista), pois a língua deve ser analisada com base nas duas categorias.

Sabe-se que a Análise do Discurso Crítica teve influência de teóricos como Bakhtin e Foucault para que se tornasse um processo de análise social e linguística. Bakhtin, apud Resende e Ramalho (2006, p. 14), como fundador da primeira teoria semiótica de ideologia e pioneiro na crítica à proposta de Saussure do objetivismo abstrato, defendeu que a linguagem não está restrita ao estudo linguístico somente, mas acontece principalmente na interação verbal, a qual é responsável pela troca entre o meio e seus participantes, como se pode verificar no fragmento:

O elemento que torna a forma linguística um signo não é sua identidade como sinal, mas sua mobilidade específica; da mesma forma que aquilo que constitui a decodificação da forma linguística não é o reconhecimento do 
sinal, mas a compreensão da palavra em seu sentido particular, isto é, a apreensão da orientação que é conferida à palavra por um contexto e uma situação precisos, uma orientação no sentido da evolução e não do imobilismo (BAKHTIN, 2002, p. 94, apud RESENDE E RAMALHO, 2006, p. 15

Michel Foucault (apud RESENDE E RAMALHO, 2006, p. 19) aborda a linguagem como espaço de luta hegemônica. Para as autoras, em uma de suas obras (Vigiar e Punir), o teórico cita e discute o exemplo de discursos usados em escolas, prisões e hospitais como forma de estabelecer disciplina. Segundo ele, essas instituições se utilizam de estratégias discursivas para fazer com que os indivíduos que passam por elas sejam moldados de acordo com a necessidade do poder. Desta forma, reforça a relação entre discurso e poder.

Portanto, é a língua que permite ao sujeito assumir uma atitude investigativa sobre o mundo, questioná-lo e questionar o conhecimento produzido, e, assim, construir sobre ele seus pontos de vista. É a língua o principal instrumento de tomada de consciência do mundo pelo sujeito.

O sujeito na Análise do Discurso não é o sujeito físico propriamente dito e sim a posição sujeito que está materializada no discurso. Orlandi (1996, p.37) afirma que "o sujeito é um lugar de significação historicamente constituído", ou seja, essa posição em que o sujeito se encontra é socialmente construída (e desconstruída) ao longo do tempo. Então, ele é uma posição entre outras e se produz entre diferentes discursos, o sujeito não vai ocupar uma única posição, mas várias, pois dependendo das condições de produção ele irá representar um papel específico.

O que diferencia o sujeito da Análise do Discurso é que este é afetado pela ideologia e pelo inconsciente. Assim, inconscientemente o sujeito interpreta o discurso a partir de suas ideologias, utilizando a história para compreender esses sentidos. É importante destacar que, na Análise do Discurso, como vai dizer Pêcheux (1988), “não há discurso sem sujeito e nem sujeito sem ideologia: o indivíduo é interpelado em sujeito pela ideologia e é assim que a língua faz sentido".

Assim, sujeito e sentido se constituem mutuamente, pois o sujeito constitui um sentido a partir da ideologia que o afeta, então a partir da ideologia ocorre um processo de formação de identidade. Orlandi (1996, p.3I) fará a seguinte definição: “A 
ideologia, por sua vez, é interpretação de sentido em certa direção, determinada pela relação da linguagem com a história em seus mecanismos imaginários”.

A ideologia, então, vai levar o sujeito a uma interpretação e não a outra. Assim, podemos dizer que é através da ideologia materializada na linguagem que o sujeito irá se manifestar, que ele irá ser agente de uma prática social. Assim sendo, podemos definir o sujeito como ser ideológico e que não tem consciência sobre essa ideologia que o constitui, a interpelação ideológica, então, não é consciente, o sujeito reproduz os discursos sem saber que estes são regidos por uma ideologia e não são seus propriamente.

Numa abordagem metalinguística, Michel Foucault, analisa a ilusão monológica do sujeito ao produzir um discurso, as ideologias subjacentes nos mesmos, o posicionamento do sujeito enquanto autor do texto, focalizando sempre o discurso como processo de interação comunicacional.

Suponho que em toda sociedade a produção do discurso é ao mesmo tempo controlada, selecionada, organizada e redistribuída por certo número de procedimentos que tem por função conjurar seus poderes e perigos, dominar seu acontecimento aleatório, esquivar sua pesada e temível materialidade (FOUCAULT, 2012, p. 8-9).

Segundo Foucault, um discurso pode ser conceituado enquanto rede de signos que se conecta a outros tantos discursos - ou a outras tantas redes de discursos -, em um sistema aberto que tanto registra quanto reproduz e estabelece os valores de determinada sociedade, perpetuando-os. O discurso, portanto, não é um encadeamento lógico de frases e palavras que pretendem um significado em si, mas, antes, ele se colocará como um importante instrumento de organização funcional que pretende estruturar determinado imaginário social. Ele - o discurso - deixa de ser um representante dos sentidos pelos quais se luta e/ou se debate para ser, então, um instrumento do desejo.

\section{CONSIDERAÇÕES FINAIS}

Observa-se aqui que dependendo do local / posição do falante o discurso muda. Por isso, ouvimos com frequência as pessoas mudando seus discursos, e isso depende da posição que exerce, da sua maturidade sobre determinado assunto, etc. Por exemplo : um colaborador de uma determinada empresa pode ficar chateado por ser 
chamado a atenção porque constantemente chega atrasado em seu local de trabalho, mas se esse mesmo individuo chega a posição de chefia vai perceber o quão bom é para a empresa que seus colaboradores sejam pontuais; veja que como esse indivíduo mudou de posição ,mudou também o seu discurso ,sendo que muitos podem até mesmo considerá-lo um hipócrita ou outras coisas mais.

Muito embora ao longo dos anos os discursos sociais tenham mudado (às vezes devido a fortes lutas pelos direitos e deveres sociais), infelizmente ainda perduram em nossa sociedade discursos de teor preconceituosos, os quais para serem mudados precisa que alcemos as nossas vozes para que as mesmas venham alardear discursos mais tolerantes e harmoniosos uns pelos outros; pois são as nossas vozes que têm influenciado a sociedade.

Sendo assim, nós devemos tomar muito cuidado com aquilo que estamos discursando, pois não existe nenhuma fala nula; uma vez que essa fala vai alcançar alguém, ou seja, alguém vai reproduzir aquilo que estamos falando. Devemos ter a noção de que através das nossas falas, nossos atos, etc. somos os responsáveis pelo tipo de sociedade que queremos formar.

\section{REFERÊNCIAS BIBLIOGRAFIAS}

BAKHTIN, Mikhail. Os gêneros do discurso. In: Estética da criação verbal. 3. ed. Trad. de Maria Ermantina Galvão; rev. de Marina Appenzeller. São Paulo: Martins Fontes, 2000. p. 277-326.

FERNANDES, Cleudemar Alves.Análise do Discurso: reflexões introdutórias. Goiania: Trihas Urbanas, 2005

FIORIN, José Luiz. Introdução ao pensamento de Bakhtin. São Paulo: Ática, 2006. FOUCAULT, Michel. A ordem do discurso: aula inaugural no Collège de France, pronunciada em 2 de dezembro de 1970. Tradução de Laura Fraga de Almeida Sampaio. São Paulo: Edições Loyola, 2012.

LEITE, Maria Regina Baraculty. Bombril e Ratinho: As vozes da sedução. In: GREGOLIN. M. R. ; BARONAS. R. Análise do Discurso: as materialidades do sentido. São Carlos: Clara 4I Luz, 200I. p. I09-I24. 
ORLANDI, E. P. Análise de discurso: Princípios e procedimentos. Campinas, SP: Pontes, 1999.

PÊCHEUX, Michel. Semântica e discurso: uma crítica à afirmação do óbvio. Tradução Eni P. Orlandi [et.al.] - Campinas, SP: editora da UNICAMP, 1997.

RESENDE, Viviane M. \& RAMALHO, Viviane. Análise de discurso crítica. São Paulo: Contexto, 2006. 